\title{
Physiology and behavior of Pseudomonas fluorescens single and dual strain biofilms under diverse hydrodynamics stresses
}

\author{
Manuel Simões ${ }^{a, b, *}$, Lúcia C. Simões ${ }^{a}$, Maria J. Vieira ${ }^{a}$ \\ a IBB-Institute for Biotechnology and Bioengineering, Centre of Biological Engineering, Universidade do Minho, Campus de Gualtar 4710-057 Braga, Portugal \\ ${ }^{\mathrm{b}}$ LEPAE, Department of Chemical Engineering, Faculty of Engineering, University of Porto, Rua Dr. Roberto Frias, s/n, 4200-465 Porto, Portugal
}

\section{A R T I C L E I N F O}

\section{Article history:}

Received 3 October 2007

Received in revised form 12 August 2008

Accepted 7 September 2008

\section{Keywords:}

Bacterial interactions

Biofilm phenotype

Biofouling

Dual biofilms

Hydrodynamic conditions

\begin{abstract}
A B S T R A C T
Three selected Pseudomonas fluorescens strains (the type strain and two strains originally isolated from a dairy processing plant - D3-348 and D3-350) were used to form turbulent and laminar flow-generated biofilms under laboratorial conditions using flow cell reactors with stainless steel substrata. The D3-348 and D3-350 strains were also used to form dual biofilms. Biofilm phenotypic characteristics, such as respiratory activity, total and culturable cells, biomass, total and matrix proteins and polysaccharides were compared. Biofilm mechanical stability, as a major feature involved in biofilm persistence, was also assessed using a rotating device system. The results indicate that hydrodynamic conditions have a remarkable impact on biofilm phenotype. Turbulent biofilms were more active, had more mass per adhesion surface area, a higher number of total and culturable cells, a higher amount of total proteins per gram of biofilm, similar matrix proteins and identical (D3-348 and D3-350 single and dual biofilms) or smaller (type strain) total and matrix polysaccharides content than their laminar counterparts. Biofilms formed by the type strain revealed a considerable higher amount of total and culturable cells and a higher amount of total proteins (turbulent biofilms) and total and matrix polysaccharides per gram of biofilm than single and dual biofilms formed by the other strains. Mechanical stability assays disclosed that biofilms formed by both type and D3-348 strains had the highest resistance to removal when exposed to mechanical stress. Dual strain biofilms population analysis revealed an apparent co-existence, evidencing neutral interactions. The overall results provided useful information regarding a broad spectrum of $P$. fluorescens biofilm phenotypic parameters, which can contribute to control and model biofilm processes in food industry.
\end{abstract}

(c) 2008 Elsevier B.V. All rights reserved.

\section{Introduction}

Microbial adhesion to abiotic surfaces and the consequent biofilm formation has been documented in many different environments (Marshall,1994; Flint et al., 1997). Biofilms constitute a protected mode of growth that allows microorganisms to survival in hostile conditions, being their phenotype significantly different from their planktonic counterparts. Differences are encountered mainly in their growth rate, biochemical composition and increased resistance to chemical antimicrobials (Cloete, 2003; Davies, 2003; Lewis, 2007). In food industry, biofilms may be a source of recalcitrant contaminations, causing food spoilage and are possible sources of public health problems such as outbreaks of foodborne pathogens (Lapidot et al., 2006; Gandhi and Chikindas, 2007). Members of the Pseudomonas genus are amongst the most diversified bacterial species in the environment and are known to be good biofilm producers (Wiedmann et al., 2000; Dogan and Boor,

\footnotetext{
* Corresponding author. LEPAE, Department of Chemical Engineering, Faculty of Engineering, University of Porto, Rua Dr. Roberto Frias, s/n, 4200-465 Porto, Portugal. Tel.: +351 225081982; fax: +351225081449.

E-mail address: mvs@fe.up.pt (M. Simões).
}

2003; Simões et al., 2005a; Olofsson et al., 2007). Particularly, P. fluorescens is a widespread bacteria in many environments, namely in dairy processing facilities, due to their short generation time, the resistance to heat treatments (Wiedmann et al., 2000; Dogan and Boor, 2003) and the ability to form biofilms (Pereira and Vieira, 2001; Simões et al., 2005b). Such characteristics provide these bacteria, especially when entrapped in biofilms, the priceless capacity to form a niche, where pathogenic microorganisms can survive.

Despite the unquestionable importance of biofilms in microbial life style and their effects on human beings, our present knowledge about the physiology and behavior of sessile communities is still limited (Simões et al., 2007a). A representative biofilm characterization is essential to the development of reliable methods for eliminating specific sources of bacterial contamination associated with biofilms (Xavier et al., 2005). As some industrial processes are flow dependent, it is expected that biofilms formed in such equipments are affected by the hydrodynamic conditions (Melo and Vieira, 1999).

Biofilm physiological changes induced by the hydrodynamic conditions have been already studied, being focused basically on single strain studies and on the characterization of biofilm morphology (thickness, surface coverage, density, viscoelasticity), growth kinetics and mass transfer events (Stoodley et al., 1999; Pereira et al., 2002; Purevdorj et al., 
2002; Rupp et al., 2005; Venugopalan et al., 2005). This study provides new data on turbulent and laminar flow-generated $P$. fluorescens biofilm phenotype, introducing also the significance of the strain variation phenomenon on single and dual strain sessile communities. In fact, in addition to the influence of operational parameters, the microbiological diversity found in biofilms formed in industrial equipment may significantly influence its own formation and behavior. Experiments in laboratory conditions using pure cultures, with well-known characteristics, contrast with real-world environments (Fux et al., 2005). In nature, most bacteria do not exist as pure cultures. Significant proportions of microorganisms are often associated as complex multi-species biofilms, performing community level processes (Møller et al., 1998). Moreover and plausibly, it appears that no bacterial strain can truly represent its own species. Microbial diversity can provide a reservoir of strains with different physiological traits that benefits the performance and resilience of the best-adapted strain alone (von Canstein et al., 2002). There are many studies showing intraspecific variation in biofilm formation for bacteria able to persist in food industry (Chae and Schraft, 2000; Norwood and Gilmour, 2001; Djordjevic et al., 2002; Ryu et al., 2004; Kim and Wei, 2007). However, the literature is scarce on the combinatory effects of changing environmental conditions, such as the flow regime, and strain variation on biofilm formation. Detailed research on this phenomenon can enhance understanding of the process and accurate quantitative description of complex biofilm systems.

The main goals of this study were to: provide an extensive quantitative phenotypic characterization of $P$. fluorescens biofilms formed under distinct hydrodynamic conditions, using three different strains (type, D3-348 and D3-350 strains); compare the phenotype of single and dual strain biofilms formed by the D3-348 and D3-350 strains and characterize their interactions in dual biofilms; assess the mechanical stability of biofilms formed by the different $P$. fluorescens strains as single and dual strain biofilms.

\section{Materials and methods}

\subsection{Bacteria}

Three Pseudomonas fluorescens strains were used throughout this work:

The type strain (13525) purchased from the American Type Culture Collection, used for monoculture studies.

The D3-348 (protease negative) and D3-350 (protease positive), two strains isolated from an overhead pipe filler in a dairy processing plant (Dogan and Boor, 2003) and kindly provided by Prof. K. J. Boor (Department of Food Science, Cornell University, Ithaca, N.Y.). Biofilm studies were performed with the D3-348 and D3-350 strains as monoculture and co-culture.

The bacteria were preserved in cryovials (Nalgene, USA) at $-80 \pm 2{ }^{\circ} \mathrm{C}$ and the growth conditions were $27 \pm 1{ }^{\circ} \mathrm{C}, \mathrm{pH} 7.0$ (0.02 M phosphate buffer $-\mathrm{KH}_{2} \mathrm{PO}_{4} ; \mathrm{Na}_{2} \mathrm{HPO}_{4}$ ), and $5 \mathrm{~g} / 1$ glucose, $1.25 \mathrm{~g} / \mathrm{l}$ yeast extract and $2.5 \mathrm{~g} / \mathrm{l}$ peptone as nutrients. All the media components were purchased from Merck (VWR, Portugal).

The bacteria were transferred no more than 3 times from the original bacterial stock in order to bacteria maintain their wild type biofilm forming characteristics. The experimental conditions used in this study did not represent the actual industrial setting from which the D3-348 and D3-350 strains were found. Nevertheless, with the tested experimental conditions the three strains had similar growth rates (Simões, 2005).

\subsection{Flow cell reactors system}

A continuous pure culture of each $P$. fluorescens was grown in a 0.51 glass chemostat (Quickfit, MAF4/41, England), at $27^{\circ} \mathrm{C}$, aerated (air flow rate $=0.425 \mathrm{l} / \mathrm{min}$ ) and agitated with a magnetic stirrer (Heidolph $\mathrm{Mr}$ 3001, Germany). The reactor was continuously fed (Ismatec Reglo,
Germany) with $10 \mathrm{ml} / \mathrm{h}$ of sterile medium containing $5 \mathrm{~g} / \mathrm{l}$ glucose, $2.5 \mathrm{~g} / \mathrm{l}$ peptone and $1.25 \mathrm{~g} / \mathrm{l}$ yeast extract in $0.02 \mathrm{M}$ phosphate buffer $\mathrm{pH}$ 7.0. The 0.51 chemostat was used to continuously inoculate $(10 \mathrm{ml} / \mathrm{h})$ a 3.51 polymethyl methacrylate (Perspex) reactor which was also aerated (air flow rate $=0.243 \mathrm{l} / \mathrm{min}$ ) and agitated with a magnetic stirrer. This reactor was fed with a diluted nutrient medium consisting of $0.05 \mathrm{~g} / \mathrm{l}$ glucose, $0.025 \mathrm{~g} / \mathrm{l}$ peptone and $0.0125 \mathrm{~g} / \mathrm{l}$ yeast extract in $0.02 \mathrm{M}$ phosphate buffer ( $\mathrm{pH} 7$ ), at a flow rate of $1.7 \mathrm{l} / \mathrm{h}$, which supported a bacterial cell density of approximately $6 \times 10^{7}$ cells $/ \mathrm{ml}$. This diluted bacterial suspension, obtained in the 3.51 reactor, was pumped up (Eheim Typ 1060 and Eheim Typ 1048 pumps), passing through two parallel flow cell reactors and back to the reactor (Fig. 1).

A flow cell reactor system, described by Pereira et al. (2002), was used as the device for biofilm formation. This device offers a simple approach to study and characterize biofilms in a well-controlled, realtime and reproducible manner (Fig. 1). It consists of a semicircular Perspex duct $\left(1.6 \times 10^{-2} \mathrm{~m}\right.$ of diameter and $4.5 \times 10^{-1} \mathrm{~m}$ of length, corresponding to a hydraulic equivalent diameter of $9.78 \times 10^{-3} \mathrm{~m}$ ) with 10 apertures on its flat wall, to suitably fit several removable rectangular pieces of Perspex, which had glued to one of its faces pieces of stainless steel (ASI $316-1.75 \times 10^{-2} \mathrm{~m} \times 1.25 \times 10^{-2} \mathrm{~m}$ ). Biofilms were formed on those metal slides whose upper faces were in contact with the bacterial suspension circulating through the flow cell reactor. Each of the rectangular pieces can be removed separately without disturbing the biofilm formed on the others and without stopping the flow. This was possible because outlet ports were disposed on the round face of the flow cell between each of the two adjacent removable pieces of Perspex that allowed the diversion of the circulating flow from the point where the reactor was opened. Two parallel similar flow cell reactors were used simultaneously in such a way that biofilms were formed under turbulent (Reynolds number $R e=5200, u=0.532 \mathrm{~m} / \mathrm{s})$ and laminar $(R e=2000, u=0.204 \mathrm{~m} / \mathrm{s})$ conditions respectively, in each flow cell. The biofilms were allowed to grow for 7 days to ensure that steady-state biofilms were used in every experiment (Pereira et al., 2002).

In the case of the dual biofilms, two independent 0.51 glass chemostats were used (one for each strain, D3-348 and D3-350). The 3.51 reactor was inoculated simultaneously with the two strains and fed with diluted nutrient medium at a flow rate two times higher $(3.4 \mathrm{l} / \mathrm{h})$ than the one used for biofilm formation by a single strain, in order to obtain the adequate dilution rate and similar to the single strain biofilm situation. The experiments were repeated at three different occasions for every condition tested.

\subsection{Biofilm sampling}

The biofilm that covered the metal slides was removed using a stainless steel scraper, resuspended into $10 \mathrm{ml}$ of buffer composed by $2 \mathrm{mM} \mathrm{Na}_{3} \mathrm{PO}_{4}, 2 \mathrm{mM} \mathrm{NaH}_{2} \mathrm{PO}_{4}, 9 \mathrm{mM} \mathrm{NaCl}$ and $1 \mathrm{mM} \mathrm{KCl}, \mathrm{pH} 7$ and homogenised by vortexing (Heidolph, model Reax top) for $30 \mathrm{~s}$ with $100 \%$ power input, according to the methodology described by Simões et al. (2005b). The homogenised biofilm suspensions were then used to sequentially assess the culturability, respiratory activity, total and matrix proteins and polysaccharides content, total cell counts and biomass.

\subsection{Culturability assessment}

Biofilm suspensions were diluted to a proper bacterial concentration in order to have formed 30-300 colony forming units (CFU) per plate. A volume of $30 \mu \mathrm{l}$ of biofilm suspensions was transferred onto plates of solid (13 g/l agar, Merck, VWR, Portugal) growth medium ( $5 \mathrm{~g} / \mathrm{l}$ glucose, $1.25 \mathrm{~g} / \mathrm{l}$ yeast extract and $2.5 \mathrm{~g} / \mathrm{l}$ peptone as nutrients). Colony enumeration was carried out after $48 \mathrm{~h}$ at $27^{\circ} \mathrm{C}$. Bacteria from dual biofilms were also streaked onto skim milk agar (Merck) in order to estimate the proportion of protease negative (D3-348) and positive bacteria (D3-350). Final values were assessed as $\mathrm{CFU} / \mathrm{cm}^{2}$. 


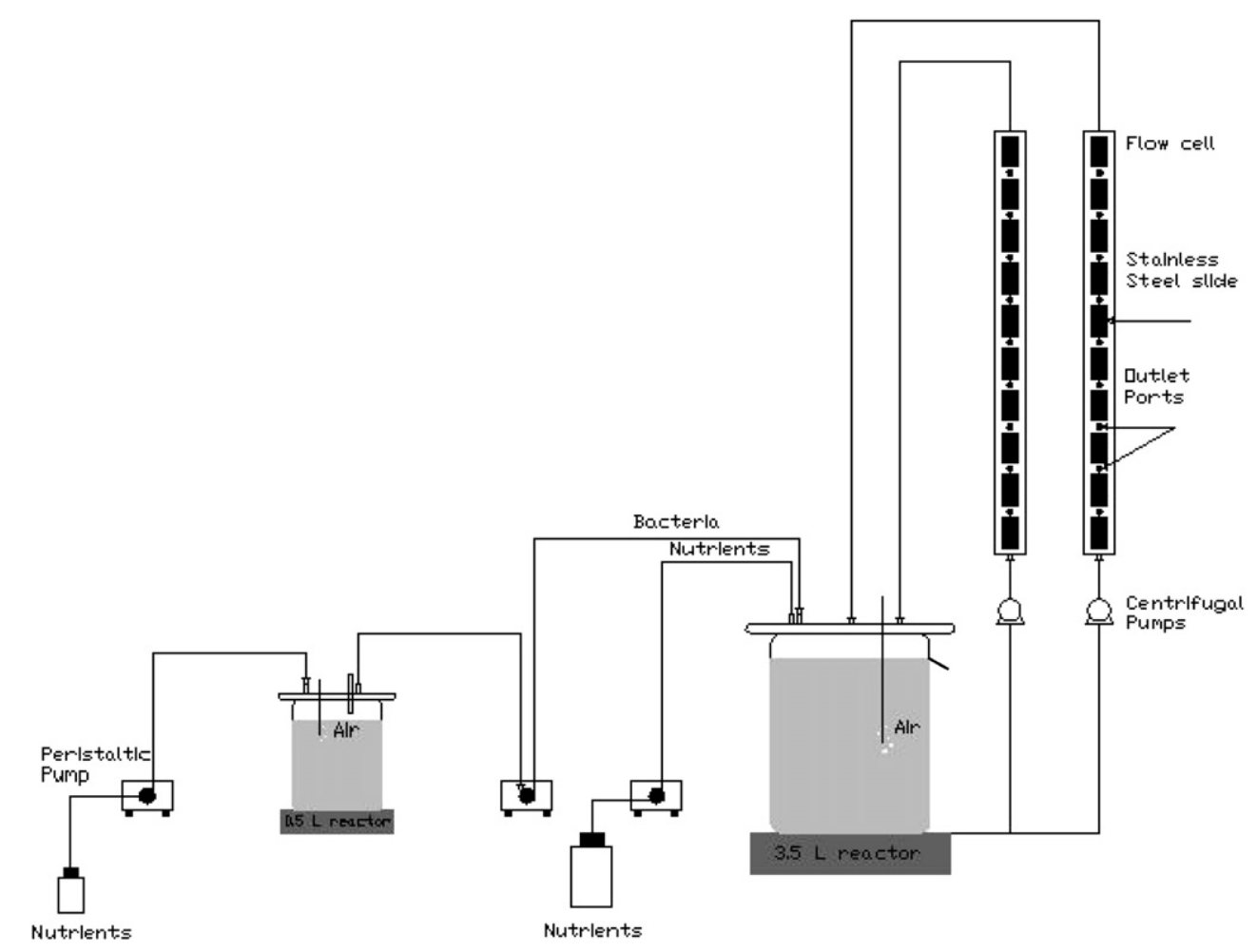

Fig. 1. Schematic representation of the experimental apparatus system used to perform biofilm formation on the flow cell reactors.

\subsection{Respiratory activity assessment}

The assays were performed in a model 53 Yellow Springs Instruments (USA) biological oxygen monitor (BOM) as described previously (Simões et al., 2005c). The samples were placed in the temperature-controlled vessel of the BOM $\left(T=27{ }^{\circ} \mathrm{C} \pm 1{ }^{\circ} \mathrm{C}\right)$. Each vessel contains a dissolved oxygen (DO) probe connected to a DO meter. Once inside the vessel, the samples were aerated for $30 \mathrm{~min}$ to ensure air saturation $\left(\left[\mathrm{O}_{2}\right]=9.2 \mathrm{mg} / \mathrm{l}\right.$, $\left.27{ }^{\circ} \mathrm{C} ; 1 \mathrm{~atm}\right)$. The vessel was closed and the decrease of oxygen concentration was monitored over time. The initial linear decrease observed corresponds to the endogenous respiration rate. To determine the oxygen uptake due to substrate oxidation, $50 \mu \mathrm{l}$ of a glucose solution (100 mg/l) was inserted into each vessel. The slope of the initial linear decrease in the DO concentration, after glucose injection, corresponded to the total respiration rate (Simões et al., 2005c). The difference between the two respiration rates gave the oxygen uptake rate due to the glucose oxidation and was expressed as $\mathrm{mg} \mathrm{O}_{2} / \mathrm{g}_{\text {biofilm }} \mathrm{min}$.

\subsection{Biomass quantification}

The dry mass of the biofilm accumulated on the slides, after the respiratory activity determination, was assessed by the determination of the total volatile solids (TVS) of the homogenised biofilm suspensions, according to Standard Methods (American Public Health Association [APHA], American Water Works Association [AWWA], Water Pollution Control Federation [WPCF], 1989), method number 2540 A-D. According to this methodology, the TVS assessed at $550 \pm 5^{\circ} \mathrm{C}$ in a furnace (Lenton thermal designs, UK) for $2 \mathrm{~h}$ is equivalent to the amount of biological mass. The biofilm mass accumulated was expressed in $\mathrm{mg}$ of dry biofilm per $\mathrm{cm}^{2}$ of surface area of the slide $\left(\mathrm{mg}_{\text {biofilm }} / \mathrm{cm}^{2}\right)$.

\subsection{Extraction of extracellular polymeric substances}

Extraction of the extracellular polymeric substances (EPS) of the biofilms was carried out using Dowex resin ( $50 \times 8, \mathrm{NA}^{+}$form, $20-50$ mesh, Fluka-Chemika, Switzerland), according to the methods of Frølund et al.
(1996). The biofilm suspension coming from the respiratory activity assessment was diluted with a volume of $10 \mathrm{ml}$ of buffer $\left(2 \mathrm{mM} \mathrm{Na}_{3} \mathrm{PO}_{4}\right.$, $2 \mathrm{mM} \mathrm{NaH}_{2} \mathrm{PO}_{4}, 9 \mathrm{mM} \mathrm{NaCl}$ and $1 \mathrm{mM} \mathrm{KCl}, \mathrm{pH}$ 7), resulting in a $20 \mathrm{ml}$ biofilm suspension. Additionally, $50 \mathrm{~g}$ of Dowex resin per $\mathrm{g}$ of volatile solids were added to the biofilms and the extraction took place at $400 \mathrm{rpm}$, using a magnetic stirrer, for $4 \mathrm{~h}$ at $4^{\circ} \mathrm{C}$. The extracellular components were separated from the cells via centrifugation $(3777 \mathrm{~g}, 5 \mathrm{~min}$ ).

\subsection{Total cell counts}

The cells separated through centrifugation from the EPS (present in the supernatant), after the extraction process, were stained with $4^{\prime}, 6$ diamidino-2-phenylindole - DAPI (Sigma, Portugal), a DNA binding stain, as described by Saby et al. (1997). The cellular pellet separated from the extracellular products was diluted to an adequate concentration (in order to have 30-250 cells per microscopic field), being thereafter microfiltrated through a Nucleopore ${ }^{\circledR}$ (Whatman, UK) black polycarbonate membrane (pore size $0.22 \mu \mathrm{m}$ ), stained with $400 \mu \mathrm{l}$ of DAPI at $0.5 \mu \mathrm{g} / \mathrm{ml}$ and left in the dark for $5 \mathrm{~min}$.

A Zeiss (AXIOSKOP, Germany) microscope fitted with fluorescence illumination with a $100 \times$ oil immersion fluorescence objective was used to visualise the cells. The optical filter combination for optimal viewing of stained preparations consisted of a $359 \mathrm{~nm}$ excitation filter in combination with a $461 \mathrm{~nm}$ emission filter. The cell observations were recorded as micrographs using a microscope camera (AxioCam HRC, Zeiss) and a program path (AxioVision, Zeiss) involving image acquisition and processing. A program path (Scan Pro 5, Sigma) involving object measurement and data output was used to quantify the number of cells.

The mean number of cells was determined from counts of a minimum of 20 microscopic fields, for each sample membrane. Final values were assessed as cells $/ \mathrm{cm}^{2}$.

\subsection{Proteins and polysaccharides}

Previous studies (Jahn et al., 1999; Pereira and Vieira, 2001) have shown that the EPS of biofilms formed by the Pseudomonas genera is 
mainly composed of proteins in addition to the polysaccharides content. Biofilm proteins were determined by the Protein Assay kit No. P 5656 provided by Sigma, using bovine serum albumin as the standard. The procedure is essentially the Lowry method (Lowry et al., 1951) as modified by Peterson (1979). The polysaccharides were determined by the phenol-sulphuric acid method of Dubois et al. (1956) with glucose as standard. The final values were assessed as mass of proteins/polysaccharides per biofilm dry mass.

\subsection{Biofilm mechanical stability}

The mechanical stability of the biofilms was assessed by means of determining the wet biomass loss due to the exposure of biofilms to increasing shear stress forces expressed as number Reynolds of agitation $\left(N^{\prime} R e_{\mathrm{A}}\right)$ in a rotating device system (Fig. 2) as described elsewhere (Azeredo and Oliveira, 2000; Simões et al., 2005b). Biofilms were grown on ASI 316 stainless steel cylinders, with a surface area of $34.6 \mathrm{~cm}^{2}$ (diameter $=2.2 \mathrm{~cm}$; length $=5 \mathrm{~cm}$ ), inserted in a 3.51 Perspex reactor and rotating (rotating device - Heidolph Type RZR1, Germany) at a $N^{\prime} R e_{\mathrm{A}}$ of 2400. Three stainless steel cylinders were used in every experiment. The $3.5 \mathrm{l}$ reactor was continuously fed $(1.7 \mathrm{l} / \mathrm{h})$ with sterile diluted medium and $P$. fluorescens suspended culture in the exponential phase of growth, as described for the flow cell reactor system. Concerning the formation of dual strain biofilms, the same approach was followed as for the flow cell reactors (two independent inocula chemostats and diluted nutrient medium at a flow rate two times higher). After 7 days of biofilm formation, the cylinders plus biofilm were carefully removed from the 3.51 reactor and the liquid and residues of biofilm on the top and on the bottom of the cylinders was removed using a stainless steel scraper and absorbent paper. This procedure was also applied after each shear stress exposure. Only the biofilm wet mass on the lateral area of the cylinder was considered for mechanical stability assessment. Under those conditions, the biofilms formed by the several strains had similar wet mass $\left(20.8 \pm 0.90 \mathrm{mg} / \mathrm{cm}^{2}\right)$ and water content $(97.1 \pm 0.77 \%)$ (Simões, 2005). This process was performed invariably during $30 \mathrm{~s}$ at $27{ }^{\circ} \mathrm{C}$. Afterwards, the biofilms were weighed and immersed in $170 \mathrm{ml}$ Perspex vessels (diameter $=4.4 \mathrm{~cm}$; length $=12 \mathrm{~cm}$ ) filled with $0.02 \mathrm{M}$ phosphate buffer ( $\mathrm{pH} 7$ ). Afterwards, the biofilms were consecutively subjected to serial shear stress forces corresponding to $N^{\prime} \operatorname{Re}_{\mathrm{A}}$ of $4000,8100,12100$, 16100 , for a period of $30 \mathrm{~s}$ each. The wet weight of the cylinders plus biofilm attached was determined before and after each $N^{\prime} R e_{\mathrm{A}}$ exposure. Fresh phosphate buffer was inserted in the $170 \mathrm{ml}$ vessels after each exposure. The experiments were repeated at three different occasions for every scenario tested.

The wet mass of the biofilm that was removed from the surface area of each cylinder, after each $N^{\prime} R e_{\mathrm{A}}$ exposure, was expressed as percentage of biofilm removal, and the amount of biofilm that remained adhered after submission to the complete series of $N^{\prime} R e_{\mathrm{A}}$ was expressed as percentage of biofilm wet mass remaining, according to the following equations:

Biofilm remaining $(\%)=\left(X_{16100}-X_{\mathrm{c}}\right) /\left(X_{\text {biofilm }}-X_{\mathrm{c}}\right) \times 100$

$\operatorname{Biofilm~removal~}_{i}(\%)=\left(X_{\text {biofilm }}-X_{i}\right) /\left(X_{\text {biofilm }}-X_{\mathrm{c}}\right) \times 100$

$X_{\text {biofilm }}$ wet mass of the biofilm plus cylinder before submission to the series of $N^{\prime} R e_{\mathrm{A}}$.

$X_{\mathrm{C}} \quad$ wet mass of the cylinder.

$i \quad N^{\prime} R_{\mathrm{A}}$, i.e., 4000, 8100, 12100 and 16100.

$X_{i} \quad$ wet mass of the biofilm plus cylinder after submission to a $N^{\prime} R e_{\mathrm{A}}$ of $4000,8100,12100$ and 16100 .

\subsection{Statistical analysis}

The data were analysed using the statistical program SPSS version 14.0 (Statistical Package for the Social Sciences). The mean and standard deviation within samples were calculated for all cases. Because low sample numbers contributed to uneven variation, nonparametric Kruskal-Wallis test was used. Statistical calculations were based on confidence level equal or higher than $95 \%$.

\section{Results}

3.1. Characterization of flow-generated biofilms - respiratory activity, biomass, total and culturable cells

Turbulent flow-generated biofilms were more active than those formed under laminar flow (Fig. 3a), independently on the strain used $(P=0.018)$. The respiratory activity of the tested biofilms was similar when developed under the same hydrodynamic conditions.

Biofilm dry mass results (Fig. 3b) show that those formed under turbulent flow had clearly more mass per adhesion surface area than the laminar counterparts $(P=0.029)$. A statistical analysis of the mass of all turbulent flow-generated biofilms revealed their similarity $(P>0.05)$. Laminar flow-generated biofilms also had similar biofilm mass.

Turbulent flow-generated biofilms had a higher number of total (Fig. 3c) and culturable (Fig. 3d) cells than those formed under laminar flow. This result is proved by a statistical significance value smaller than 0.05 for the four scenarios studied. The type strain formed both turbulent and laminar biofilms with the highest number of total $(P=0.002-$ turbulent; $P=0.013$ - laminar) and culturable cells ( $P=0.008$ - turbulent; $P=0.021$ - laminar) comparatively to those formed by the other strains. The comparison between Fig. 3c and d shows that most biofilm cells are

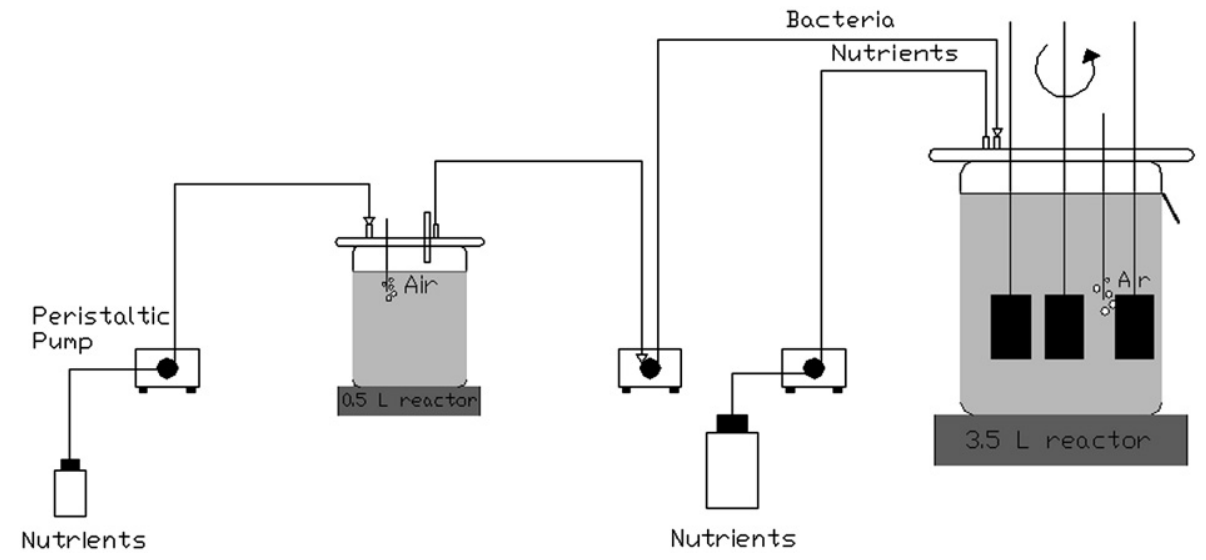

Fig. 2. Schematic representation of the experimental system used to perform biofilm formation on the bioreactor rotating system used for mechanical stability studies. 

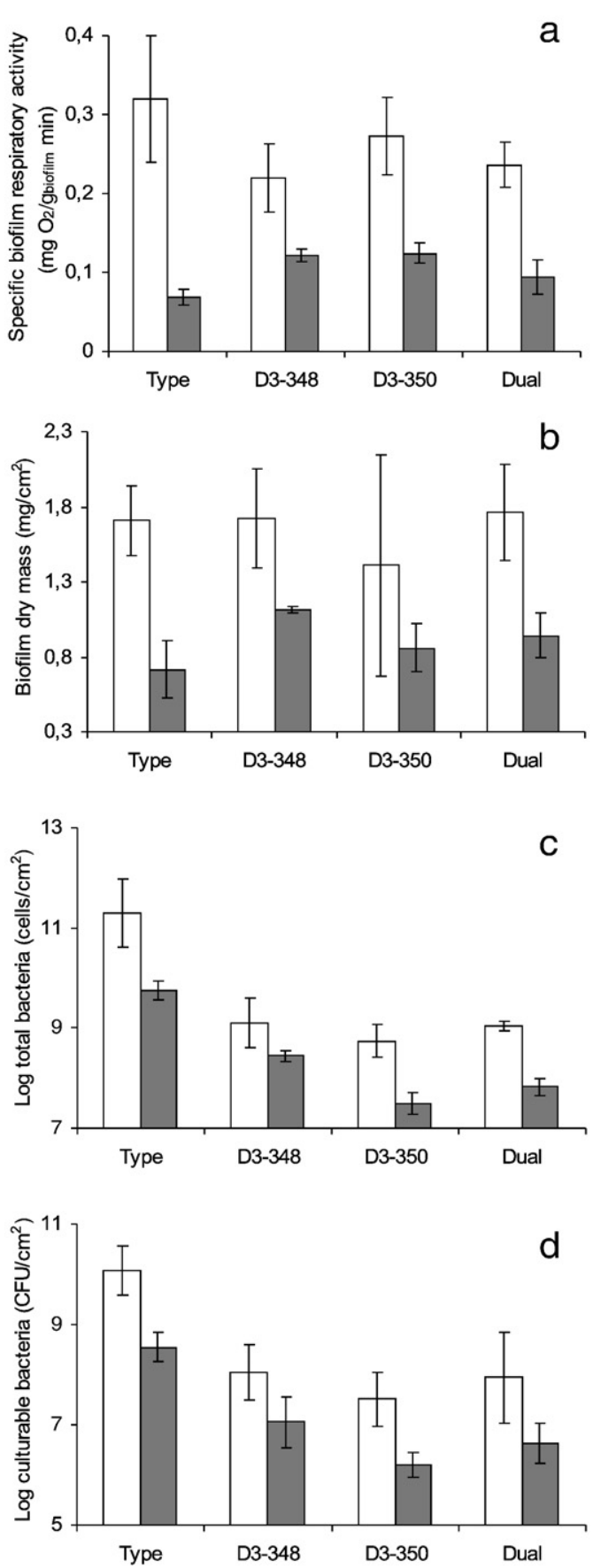

Fig. 3. Biofilm respiratory activity (a), dry mass (b), total (c) and culturable (d) cells of the several 7 days old $P$. fluorescens single and dual turbulent $(\square)$ and laminar ( $\square$ ) flowgenerated biofilms formed on stainless steel surfaces using flow cell reactors. Each symbol indicates the mean $\pm \mathrm{SD}$ of at least three independent experiments.

not culturable $(P=0.003)$. The decreased ability of biofilm cells to grow in solid medium was independent on the hydrodynamic conditions under which biofilms were developed and on strain variability. A difference of $1.21 \pm 0.39 \log \mathrm{CFU} / \mathrm{cm}^{2}(91.7 \pm 5.99 \%$ of the total population) between culturable and total cells was detected for the tested biofilms. The analysis of dual strain biofilm community, in terms of relative abundance through the assessment of CFU on skim milk agar, revealed an equal colonization by both strains. Turbulent flow-generated biofilms were colonized by log values of $7.61 \pm 0.43 \mathrm{CFU} / \mathrm{cm}^{2}$ (D3-348) and $7.67 \pm 0.70 \mathrm{CFU} / \mathrm{cm}^{2}$ (D3-350), while laminar flow-generated biofilms had log values of $6.35 \pm 0.21 \mathrm{CFU} /$ $\mathrm{cm}^{2}$ and $6.29 \pm 0.35 \mathrm{CFU} / \mathrm{cm}^{2}$ of D3-348 and D3-350 strains respectively.
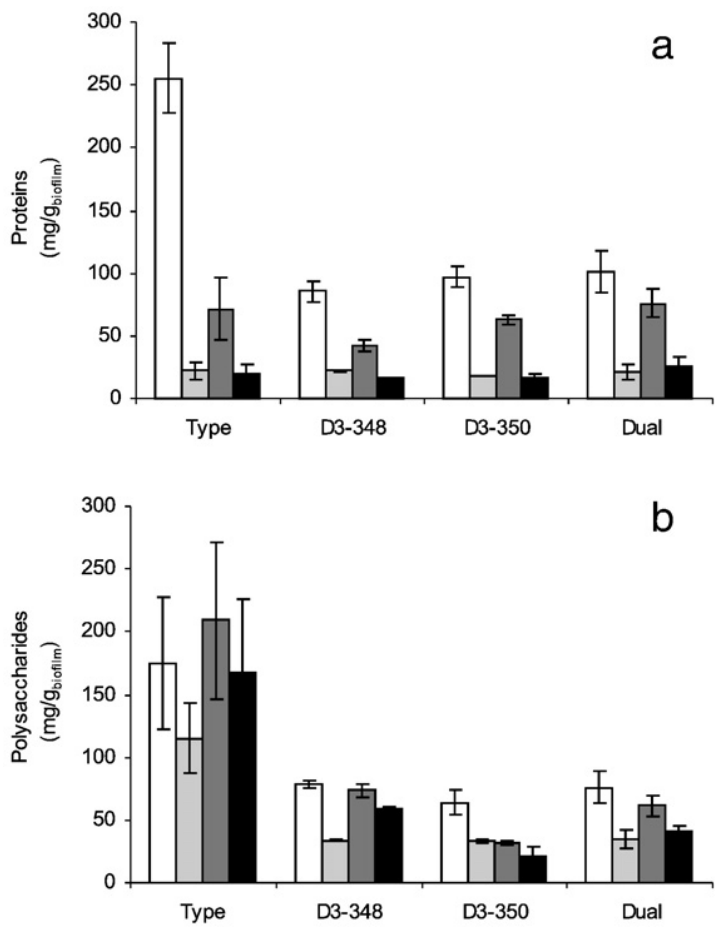

Fig. 4. Total and matrix proteins (a) and polysaccharides (b) content per gram of biofilm of the several 7 days old P. fluorescens single and dual turbulent (total $-\square$; matrix $-\square$ ) and laminar (total $-\square$; matrix - $\mathbf{0}$ ) flow-generated biofilms formed on stainless steel surfaces using flow cell reactors. Each symbol indicates the mean \pm SD of at least three independent experiments.

\subsection{Characterization of flow-generated biofilms - organic constituents}

Analysis of biofilm organic constituents shows that turbulent flowgenerated biofilms had a higher amount of total proteins per gram of biofilm (Fig. $4 a)$ than the laminar counterparts $(P=0.033)$. The tested laminar flow-generated biofilms were composed by similar total proteins amount. Turbulent biofilms formed by the type strain had a significant higher amount of total proteins than single and dual biofilms formed by the other strains $(P=0.008)$. These single and dual biofilms had equivalent total proteins content per gram of biofilm.

Matrix proteins content was comparable for turbulent and laminar flow-generated biofilms formed by the distinct strains/associations. Analysing the proportion of matrix proteins, it represents about 9\% (turbulent) and 30\% (laminar) of the total proteins for biofilms formed by the type strain, while the single and dual biofilms formed by the D3-348 and D3-350 strains had about 20\% (turbulent), 30\% (laminar -

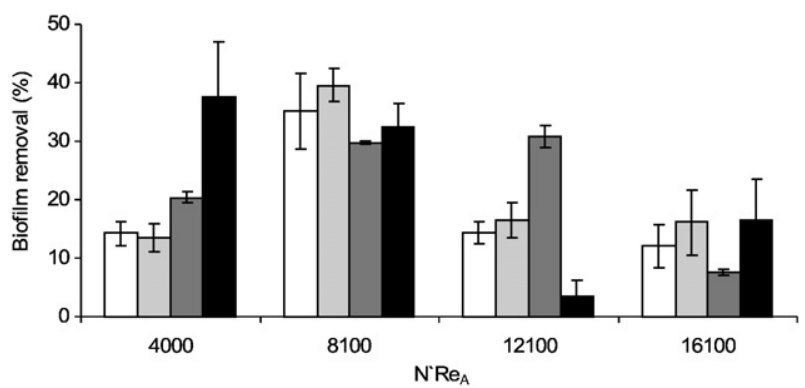

Fig. 5. Biofilm removal, expressed as percentage of wet mass removed, due to the exposure to increasing $N^{\prime} R e_{\mathrm{A}}$. Biofilms were developed for 7 days on stainless steel cylindrical surfaces at a constant $N^{\prime} R e_{\mathrm{A}}$ of 2400 using the bioreactor rotating system. $\square-$ Type; $\square-$ D3-348; $\square-$ D3-350; - dual. Each symbol indicates the mean \pm SD of at least three independent experiments. 


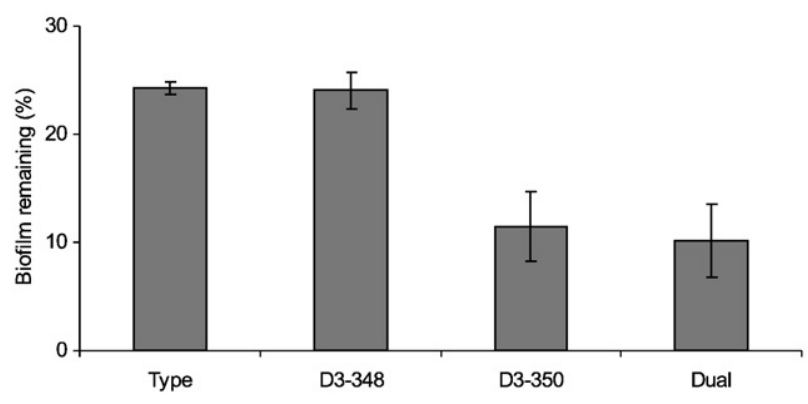

Fig. 6. Biofilm remaining, expressed as percentage of wet mass remaining adhered, for the single and dual strain biofilms posterior to the exposure to the total series of $N^{\prime} R e_{\mathrm{A}}$. Biofilms were developed for 7 days on stainless steel cylindrical surfaces at a constant $N^{\prime} R e_{\mathrm{A}}$ of 2400 using the bioreactor rotating system. Each symbol indicates the mean \pm SD of at least three independent experiments.

D3-350 single biofilms, and dual biofilms) and 40\% (laminar - D3-348 single biofilms) of the total proteins.

Biofilms formed by the type strain had a significant higher amount of total polysaccharides per gram of biofilm (Fig. 4b) than those formed by the other strains ( $P=0.013$ - turbulent; $P=0.008$ - laminar). Moreover, type strain laminar flow-generated biofilms had a higher content of total polysaccharides than the turbulent counterparts $(P=0.033)$. Single and dual biofilms formed by the D3-348 and D3-350 strains formed under turbulent and laminar flow were composed by comparable amounts of total polysaccharides.

Matrix polysaccharides content (Fig. 4b) were different when comparing turbulent and laminar flow-generated biofilms $(P=0.037)$. Biofilms formed by the type strain exhibited a higher amount of matrix polysaccharides of both turbulent $(P=0.014)$ and laminar $(P=0.005)$ flow-generated biofilms, than those formed by the D3-348 and D3-350 strains. These strains produced single and dual biofilms, under both hydrodynamic conditions, with similar matrix polysaccharides content. The percentage of matrix polysaccharides assessment in the total polysaccharides shows that turbulent flow-generated single and dual biofilms formed by the D3-348 and D3-350 strains were composed by approximately $50 \%$ of the total polysaccharides, while those formed by the type strain had about $66 \%$ of the total polysaccharides as matrix constituents. The matrix of the laminar flow-generated biofilms was composed by $85 \%$ (type and D3-348 strain single biofilms) and 70\% (D3-350 single biofilms, and dual biofilms) of the total polysaccharides.

\subsection{Biofilm mechanical stability}

The exposure of biofilms to incrementing $N^{\prime} e_{\mathrm{A}}$ caused removal. This process was dependent on the $N^{\prime} R e_{\mathrm{A}}$ to which the four biofilms were exposed (Fig. 5). The high percentage of removal occurred with the application of $N^{\prime} R e_{\mathrm{A}}$ of 4000 (dual biofilms), 8100 (type and D3-348), and 12100 (D3-350). Comparing wet biomass removal for the tested biofilms and for the same $N^{\prime} R e_{\mathrm{A}}$, differences were found for $N^{\prime} R e_{\mathrm{A}}$ of $4000(P=0.024)$ and $12100(P=0.009)$.

Fig. 6 shows that biofilm exposure to increasing $N^{\prime} R e_{\mathrm{A}}$ did not give rise to total biofilm removal, as only about 76\% (type and D3-348), 88\% (D3-350) and 90\% (dual) of biofilm wet mass were detached from the cylinders, demonstrating the failure of the mechanical treatment to eradicate biofilms and that those formed by both type and D3-348 strain presented higher mechanical stability than those formed by D3-350 strain and D3-348/D3-350 co-culture.

\section{Discussion}

The study of the parameters influencing biofilm formation and behavior represents a valuable tool for biofilm basic understanding and control (Xavier et al., 2005). This study shows that P. fluorescens turbulent flow-generated biofilms are physiologically distinct from those formed under laminar flow. This fact is evident for every tested strain grown as monoculture or co-culture. Turbulent flow-generated biofilms were more active, had more mass per $\mathrm{cm}^{2}$, higher number of total and culturable cells, higher amount of total proteins per gram of biofilm, similar matrix proteins and identical (single and dual biofilms of D3-348 and D3-350 strains) or smaller (type strain biofilm) total and matrix polysaccharides content per gram of biofilm in comparison to laminar flow-generated biofilms. A higher physiological heterogeneity is found for biofilms formed under turbulent conditions. This is evident when comparing the standard deviations calculated from biofilm mass, respiratory activity and culturability data. Biofilms are recognized as physiologically heterogenic communities (Stewart and Franklin, 2008), and based on our results the turbulent flow seems to accentuate this phenomenon. Moreover, the distinct metabolic activity of turbulent and laminar flow-generated biofilms is arguably related with the different passive transport of cells, oxygen and nutrients through the biofilm, deriving from the flow conditions (Stoodley et al., 1997; 1999; Pereira et al., 2002). In fact, during enhanced flow and turbulence, nutrients and oxygen could be transported into the biofilm microenvironment and be responsible for the majority of the altered bacterial metabolism (Stoodley et al., 1997). Consequently, the higher oxygen rate and substrate transport from the fluid to the biofilm, should favour microbial metabolism and cell replication. Additionally, studies analysing the electron transport system shown that high shear stress can stimulate biofilm catabolic activity (Liu and Tay, 2001).

The numbers of total and culturable biofilm cells were not comparable for the tested biofilms, which is probably related to the limitations of the plate count method. In a previous study (Simões et al., 2007b), it was found that, using viability stains and epifluorescence microscopy, turbulent and laminar flow-generated biofilms formed by the type strain had more than $99.5 \%$ of the population in viable state. Similar results were also found for the other tested strains (Simões, 2005). In fact, it has long been recognized that the use of culture-based enumeration techniques may significantly underestimate the numbers of viable cells. Several reasons may account for this difference: (i) the presence of starved or injured cells or potentially viable but nonculturable cells (VBNC) that are not able to initiate cell division at a sufficient rate to form colonies; (ii) inadequate culture conditions; (iii) aggregation of bacteria that can lead to the formation of one colony from more than one cell, thereby underestimating the total number of cells (Banning et al., 2002).

Biofilm phenotypic characterization clearly shows that all the strains formed laminar flow-generated biofilms with a relative (matrix concentration/total concentration) higher content of matrix proteins and polysaccharides per gram of biofilm than the turbulent counterparts. These differences can account for the different structure of $P$. fluorescens type strain turbulent and laminar flow-generated biofilms reported by Pereira et al. (2002). These authors found that laminar flow-generated biofilms had a higher thickness $(28 \pm 12 \mu \mathrm{m})$ than the turbulent counterparts $(22 \pm 8 \mu \mathrm{m})$, although the cellular density and mass of these biofilms is significantly different, as verified in the present study. In fact, the hydrodynamic conditions under which the biofilms are formed can cause other phenotypic differences. As example, type strain turbulent flow-generated biofilm cells had equivalent spherical radius, determined through cell lengths and widths measurements (Walker et al., 2005), of $0.201 \pm 0.01 \mu \mathrm{m}$ comparatively to $0.408 \pm 0.03 \mu \mathrm{m}$ of laminar flow-generated biofilm cells (Simões et al., 2007b). Moreover, turbulent and laminar flow-generated biofilm cells, mainly those formed by the type strain, were in a considerable higher amount than those found in industrial environments (Sharma and Anand, 2002). The high biofilm cell counts reported are apparently related with the characteristics of the experimental system used. In fact, the bioreactor system and the operating conditions used were optimized to improve the potential of bacteria to form biofilms and to mimic industrial flow processes (Azeredo and Oliveira, 2000; Pereira et al., 2002). 
Dual strain biofilms failed to show remarkable differentiation as a consequence of potential interactions promoted by the D3-348 and D3-350 strains. The physiological characteristics of dual biofilms seem to represent an average of the values of each single strain biofilm, evidencing neutral interactions between D3-348 and D3-350 strains. This is reinforced by the similar CFU counts. However, more data is required to confirm this degree of interaction. Previous studies using Pseudomonas spp. in dual species biofilms (Cowan et al., 2000) demonstrated the potential for commensal interactions when in the presence of organic compounds. Other apparent protective effects caused by microorganisms association have been mentioned (Leriche et al., 2002; Lindsay et al., 2002; Whiteley et al., 2002). According to Camper et al. (1996), the initial growth rate appeared to have a significant impact on microbial ability to compete in a dual population biofilm. In fact, in this study, the tested strains, as single or co-cultured, had similar growth rates (Simões, 2005) explaining the co-existence and the apparent neutral interactions found within the dual strain biofilms.

The mechanical stability of biofilms, defined as their responsive behavior to mechanical stress conditions, revealed that the exposure of biofilms to shear stress forces higher than the one under which the biofilm was formed caused biomass removal. Nevertheless, complete biofilm removal was not observed. According to some authors (Stoodley et al., 1999; Körstgens et al., 2001), the biofilm matrix develops an inherent internal tension, which is in equilibrium with the shear stress under which the biofilm was formed, and the removal of a wellestablished biofilm requires the overcome of the forces that keep the matrix together as well as the forces that bound the biofilm to the adhesion surface. Those latter reports support the data obtained in this study, as for the several biofilms high removal was achieved with the sudden increase in the $N^{\prime} e_{A}$ of 8100 (type and D3-348), 12100 (D3-350) and 4000 (dual biofilms). Mechanical stability experiments also demonstrated the higher resistance to removal of single biofilms formed by the type and D3-348 strains when comparing with the other biofilms. Concerning biofilm remaining of D3-350 single and the dual strain biofilms, the similarity observed could be due to the prevalence of this strain in the inner layers of the dual biofilms. In fact, biofilm removal, using the rotating device system, is known to be processed in layers (Azeredo and Oliveira, 2000). If D3-350 strain was near the stainless steel surface, removal was then facilitated. The mechanical stability results also reinforces that the association of the D3-348 and D3-350 strains in dual biofilms formed a functional system where both strains were maintained with an apparent lack of interaction, not generating biofilms with a relevant distinct mechanical stability from the single ones.

Biofilms formed by the type strain represent the worst case scenario, in a biofilm control context by conventional chemical and mechanical treatments. This is due to the more complex matrix, higher cell numbers and advantageous mechanical stability, comparatively to the other tested biofilms. The barrier protection provided by the biofilm EPS matrix increase the resistance and resilience of biofilm-resident bacteria to environmental stress conditions, while the higher cellular density can provide a decreased ratio of antimicrobial agent concentration per target cell (Stewart et al., 2000; Pereira and Vieira, 2001; Simões et al., 2003; 2006). In previous studies (Simões et al., 2003, 2005a), it was demonstrated that the biofilm physiology, derived from the flow regime under which the biofilms were developed, had a strong impact on their control by the action of disinfectants. Biofilms formed under turbulent flow were more resistant than those formed under laminar conditions.

The overall results allow to conclude that hydrodynamic conditions influence markedly the phenotype of $P$. fluorescens biofilms. Turbulent flow-generated biofilms were more active, had more mass per surface area, a higher number of total and culturable cells and total proteins content per gram of biofilm, similar matrix proteins and identical (single and dual biofilms formed by D3-348 and D3-350 strains) or smaller (type strain biofilms) total and matrix polysaccharides content than laminar biofilms. D3-348 and D3-350 strains co-existed in dual biofilms with apparent neutral interactions. Mechanical stability assays disclosed that biofilms formed by both type and D3-348 strains show a higher resistance to removal when exposed to mechanical stress. As a consequence, the type strain represents, apparently, the worst case (meaning the toughest to remove and hence, the most well adapted to the cultivation conditions) in a biofilm control process when comparing with the other single and dual strain biofilms. This fact addresses a timely topic, as there is increasing awareness that domesticated laboratorial strains are not adequate models for biofilm formation and control (Fux et al., 2005). However, the experimental conditions used in this study were not intended to reproduce the industrial settings from which the D3-348 and D3-350 strains were collected. Further evidences are required to demonstrate that the domesticated type strain, when in the actual industrial setting, would be able to perform better than the environmental strain present there.

\section{Acknowledgments}

The authors acknowledge the financial support provided by the Portuguese Foundation for Science and Technology (Project BiomodePTDC/BIO/73550/2006, PhD grant-Lúcia Simões. We gratefully acknowledge Prof. Kathryn J. Boor (Department of Food Science, Cornell University, Ithaca, N.Y.) for providing the D3-348 and D3-350 strains.

\section{References}

APHA, AWWA, WPCF, 1989. In: Clesceri, L.S., Greenberg, A.E., Trussel, R.R. (Eds.), Standard Methods for the Examination of Water and Wastewater, 17th ed. American Public Health Association, Washington, D.C.

Azeredo, J., Oliveira, R., 2000. The role of exopolymers produced by Sphingomonas paucimobilis in biofilm formation and composition. Biofouling 16, 17-27.

Banning, N., Toze, S., Mee, B.J., 2002. Escherichia coli survival in groundwater and effluent measured using a combination of propidium iodide and the green fluorescent protein. Journal of Applied Microbiology 93, 69-76.

Camper, A.K., Jones, W.L., Hayes, J.T., 1996. Effect of growth conditions and substratum composition on the persistence of coliforms in mixed-population biofilms. Applied and Environmental Microbiology 62, 4014-4018.

Chae, M.S., Schraft, H., 2000. Comparative evaluation of adhesion and biofilm formation of different Listeria monocytogenes strains. International Journal of Food Microbiology 5, 103-111.

Cloete, T.E., 2003. Resistance mechanisms of bacteria to antimicrobial compounds. International Biodeterioration \& Biodegradation 51, 277-282.

Cowan, S.E., Gilbert, E., Liepman, D., Keasling, J.D., 2000. Commensal interactions in a dual-species biofilm exposed to mixed organic compounds. Applied and Environmental Microbiology 66, 4481-4485.

Davies, D., 2003. Understanding biofilm resistance to antibacterial agents. Nature Reviews in Drug Discovery 2, 114-122.

Djordjevic, D., Wiedmann, M., McLandsborough, L.A., 2002. Microtiter plate assay for assessment of Listeria monocytogenes biofilm formation. Applied and Environmental Microbiology 68, 2950-2958.

Dogan, B., Boor, K.J., 2003. Genetic diversity and spoilage potential among Pseudomonas spp. isolated from fluid milk products and dairy processing plants. Applied and Environmental Microbiology 69, 130-138.

Dubois, M., Gilles, K.A., Hamilton, J.K., Rebers, A., Smith, F., 1956. Colorimetric method for determination of sugars and related substances. Analytical Chemistry 28, 350-356.

Flint, S.H., Bremer, P.J., Brooks, J.D., 1997. Biofilms in dairy manufacturing plant description, current concerns and methods of control. Biofouling 11, 81-97.

Frølund, B., Palmgren, R., Keiding, A., Nielsen, P.H., 1996. Extraction of extracellular polymers from activated sludge using a cation exchange resin. Water Research 30, 1749-1758.

Fux, C.A., Shirtliff, M., Stoodley, P., Costerton, J.W., 2005. Can laboratory reference strains mirror "real-world" pathogenesis. Trends in Microbiology 13, 58-63.

Gandhi, M., Chikindas, M.L., 2007. Listeriaa foodborne pathogen that knows how to survive. International Journal of Food Microbiology 113, 1-15.

Jahn, A., Griebe, T., Nielsen, P.H., 1999. Composition of Pseudomonas putida biofilms: accumulation of protein in the biofilm matrix. Biofouling 14, 49-57.

Kim, S.H., Wei, C.I., 2007. Biofilm formation by multidrug-resistant Salmonella enterica serotype Typhimurium phage type DT104 and other pathogens. Journal of Food Protection 70, 22-29.

Körstgens, V., Flemming, H.-C., Wingender, J., Borchard, W., 2001. Uniaxial compression measurement device for investigation of the mechanical stability of biofilms. Journal of Microbiological Methods 46, 9-17.

Lapidot, A., Romling, U., Yaron, S., 2006. Biofilm formation and the survival of Salmonella Typhimurium on parsley. International Journal of Food Microbiology 3, 229-233.

Leriche, V., Briandet, R., Carpentier, B., 2002. Ecology of mixed biofilms subjected daily to a chlorinated alkaline solution: spatial distribution of bacterial species suggests a protective effect of one species to another. Environmental Microbiology 5, 64-71.

Lewis, K., 2007. Persister cells, dormancy and infectious disease. Nature Reviews in Microbiology 5, 48-56. 
Lindsay, D., Brözel, V.S., Mostert, J.F., von Holy, A., 2002. Differential efficacy of a chlorine dioxide-containing sanitizer against single and dual biofilms of a dairy-associated Bacillus cereus and a Pseudomonas fluorescens isolate. Journal of Applied Microbiology 92, 352-361.

Liu, Y., Tay, J.H., 2001. Detachment forces and their influence on the structure and metabolic behaviour of biofilms. World Journal of Microbiology and Biotechnology 17, 111-117.

Lowry, O.H., Rosebrough, N.L., Farr, A.L., Randall, K.J., 1951. Protein measurement with the Folin-phenol reagent. Journal of Biological Chemistry 193, 265-275.

Marshall, K.C., 1994. Microbial adhesion in biotechnological processes. Current Opinion in Biotechnology 5, 296-301.

Melo, L.F., Vieira, M.J., 1999. Physical stability and biological activity of biofilms formed under turbulent flow and low substrate concentration. Bioprocess Engineering 20, 363-368.

Møller, S., Steinberg, C., Andersen, J.B., Christensen, B.B., Ramos, J.L., Givskov, M., Molin, S 1998. In situ-culture biofilms: evidence of metabolic interactions between community members. Applied and Environmental Microbiology 64, 721-732.

Norwood, D.E., Gilmour, A., 2001. The differential adherence capabilities of two Listeria monocytogenes strains in monoculture and multispecies biofilms as a function of temperature. Letters in Applied Microbiology 33, 320-324.

Olofsson, T.C., Ahrné, S., Molin, G., 2007. Composition of the bacterial population of refrigerated beef, identified with direct 16S rRNA gene analysis and pure culture technique. International Journal of Food Microbiology 118, 233-240.

Pereira, M.O., Vieira, M.J., 2001. Effects of the interactions between glutaraldehyde and the polymeric matrix on the efficacy of the biocide against Pseudomonas fluorescens biofilms. Biofouling 17, 93-101.

Pereira, M.O., Kuehn, M., Wuertz, S., Neu, T., Melo, L., 2002. Effect of flow regime on the architecture of a Pseudomonas fluorescens biofilms. Biotechnology and Bioengineering 78, 164-171.

Peterson, G.L., 1979. Review of the Folin Phenol quantitation method of Lowry, Rosenburg, Farr and Randall. Analytical Biochemistry 100, 01-220.

Purevdorj, B., Costerton, J.W., Stoodley, P., 2002. Influence of hydrodynamics and cell signalling on the structure and behaviour of Pseudomonas aeruginosa biofilms. Applied and Environmental Microbiology 68, 4457-4464.

Rupp, C.J., Fux, C.A., Stoodley, P., 2005. Viscoelastic of Staphylococcus aureus biofilms in response to fluid shear allows resistance to detachment and facilitates rolling migration. Applied and Environmental Microbiology 71, 2175-2178.

Ryu, J.H., Kim, H., Frank, J.F., Beuchat, L.R., 2004. Attachment and biofilm formation on stainless steel by Escherichia coli 0157:H7 as affected by curli production. Letters in Applied Microbiology 39, 359-362.

Saby, S., Sibille, L., Mathiew, L., Paquin, J.L., Block, J.C., 1997. Influence of water chlorination on the counting of bacteria with DAPI (4,6-diamino-2-phenylindole) Applied and Environmental Microbiology 63, 1564-1569.

Sharma, M., Anand, S.K., 2002. Biofilms evaluation as an essential component of HACCP for food/dairy processing industry-a case. Food Control 13, 469-477.

Simões, M., 2005. Use of biocides and surfactants to control Pseudomonas fluorescens biofilms-role of hydrodynamic conditions. PhD Thesis. University of Minho.

Simões, M., Pereira, M.O., Vieira, M.J., 2003. Effect of different concentrations of orthophthalaldehyde on biofilms formed by Pseudomonas fluorescens under different flow conditions. Biofouling 19, 287-295.
Simões, M., Pereira, M.O., Vieira, M.J., 2005a. Action of a cationic surfactant on the activity and removal of bacterial biofilms formed under different flow regimes. Water Research 39, 478-486.

Simões, M., Pereira, M.O., Vieira, M.J., 2005b. Effect of mechanical stress on biofilms challenged by different chemicals. Water Research 39, 5142-5152.

Simões, M., Pereira, M.O., Vieira, M.J., 2005c. Validation of respirometry as short-term method to assess the toxic effect of a biocide. Biofouling 21, 9-17.

Simões, M., Simões, L.C., Machado, I., Pereira, M.O., Vieira, M.J., 2006. Control of flowgenerated biofilms using surfactants-evidence of resistance and recovery. Food and Bioproducts Processing 84, 338-345.

Simões, M., Pereira, M.O., Vieira, M.J., 2007a. Influence of biofilm composition on the resistance to detachment. Water Science and Technology 55, 473-480.

Simões, M., Pereira, M.O., Sillankorva, S., Azeredo, S., Vieira, M.J., 2007b. The effect of hydrodynamic conditions on the phenotype of Pseudomonas fluorescens biofilms. Biofouling 23, 249-258.

Stewart, P.S., Franklin, M.J., 2008. Physiological heterogeneity in biofilms. Nature Reviews in Microbiology 6, 199-210.

Stewart, P.S., McFeters, G.A., Huang, C.-T., 2000. Biofilm control by antimicrobial agents. In: Bryers, J.D. (Ed.), Biofilms II: Process Analysis and Applications. Wiley-Liss, New York, pp. 373-405.

Stoodley, P., Yang, S., Lappin-Scott, H.-M., Lewandowski, Z., 1997. Relationship between mass transfer coefficient and liquid flow velocity in heterogenous biofilms using microelectrodes and confocal microscopy. Biotechnology and Bioengineering 56, 681-688.

Stoodley, P., Lewandowski, Z., Boyle, J.D., Lappin-Scott, H.-M., 1999. Structural deformation of bacterial biofilms caused by short-term fluctuations in fluid shear: an in situ investigation of biofilm rheology. Biotechnology and Bioengineering 65, 83-92.

Venugopalan, V.P., Kuehn, M., Hausner, M., Springael, D., Wilderer, P.A., Wuertz, S., 2005 Architecture of a nascent Sphingomonas sp. biofilm under varied hydrodynamic conditions. Applied and Environmental Microbiology 71, 2677-2686.

von Canstein, H., Kelly, S., Li, Y., Wagner-Döbler, I., 2002. Species diversity improves the efficiency of mercury-reducing biofilms under changing environmental conditions. Applied and Environmental Microbiology 68, 2829-2837.

Walker, L.W., Hill, J.E., Redman, J.A., Elimelech, M., 2005. Influence of growth phase on adhesion kinetics of Escherichia coli D21g. Applied and Environmental Microbiology 71, 3093-3099.

Whiteley, M., Ott, J.R., Weaver, E.A., McLean, R.J., 2002. Effects of community composition and growth rate on aquifer biofilm bacteria and their susceptibility to betadine disinfection. Environmental Microbiology 3, 43-52.

Wiedmann, M., Weilmeier, D., Dineen, S.S., Malyea, R., Boor, K.J., 2000. Molecular and phenotypic characterization of Pseudomonas sp. isolated from milk. Applied and Environmental Microbiology 66, 2085-2095.

Xavier, J.B., Picioreanu, C., Rani, S.A., van Loosdrecht, C.M., Stewart, P.S, 2005. Biofilmcontrol strategies based on enzymatic disruption of the extracellular polymeric substance matrix-a modelling study. Microbiology 151, 3817-3832. 